\title{
TEAM APPROACH TO THE PSYCHOLOGICAL TREATMENT OF PATIENTS WITH SPINAL CORD INJURY
}

\author{
By José B. Cibeira and ERnesto c. Liendo \\ The National Institute of Rehabilitation, Buenos Aires, Argentina
}

INTRODUCTION

This paper discusses a therapeutic programme involving 615 patients suffering from spinal cord injury. In this therapeutic programme we have emphasised the harmony and coherence of the psychologic therapeutic means employed rather than an isolated definite technique.

We have tried to deal with the three areas of patient; behaviour, body and mind, and society. This has basically been the work of the therapeutic team co-ordinator in charge of each paraplegic. These medical doctors themselves have been under the director of the centre's supervision. Metaphorically speaking, it could be said that the components of each therapeutic team acted as 'executives', in the enterprise of providing help to the paraplegic, while the different co-ordinators, under the director's supervision, became the 'decision makers' of such an enterprise. Accordingly, it was for the co-ordinator to detect the institutional emergency point, for the medical specialist to detect the organic emergency point for the psychotherapist, the psychic emergency point and for the social worker and the teacher, the vocational emergency points.

Taking into consideration all these elements we have considered the patient's psychological and psycho-social evaluation from a four-fold perspective: diagnostic, prognostic, therapeutic and prophylactic.

\section{DIAGNOSIS}

Initially, we have to deal with a pathoneurotic or pathopsychotic picture according to how the patient's previous personality decompensated when it had to face and accept such an invalidating organic disease as paraplegia.

We assign basic importance to a proper initial diagnostic hypothesis including the patient's personality, family environment, socio-vocational context and the therapeutic means used to help the paraplegics.

(a) Based on an initial interview with the patient we obtained a diagnostic and prognostic outline centred on what the patient wanted to obtain and what he feared might happen to him, both in his vital-personal future and his relation with the medical team during his treatment, i.e. what he expected and what he feared. In general, he wished the attending physician to behave approximately as the parental figure that protected him when he was a child, and was afraid he would behave as the figure he specifically feared as a child. (By using this type of procedure we were able to detect the patient's specific fear and desires; and also his specific and individual expectation of the physician's and his team's behaviour.)

(b) The first level or psycho-social level consisted in determining the leading function carried out in his home environment by the paraplegic patient before he 
became ill. Obviously it was not the same to deal with a patient who had been a passive parent when compared with a patient who had been an active one, his family's foundation.

In the later case for instance, the family group would be able to replace his role with much more difficulty.

The second, diagnostic or socio-dynamic level deals with the behaviour of the family as a whole. For instance, an hypomaniac group, highly connected with the community, or a closed, epileptoid group. The latter was more difficult to work on, when dealing with the paraplegic at group level.

The third or social level deals with the social class to which the patient group belongs (low, median, high) and its vertical mobility (ascending, static or descending). We were able to notice that a paraplegic belonging to the low class being unable to participate in the intense social and sport characteristic of his class, had more difficulties in working out his problem than a patient belonging to the middle class who is more domestic and beaurocratic. And inversely, a paraplegic belonging to the high class or to the low class would have a better community extra familial backing than a paraplegic of the middle class belonging to a more isolated and individualistic family group.

\section{PROGNOSIS}

The classical stages of mourning, stupor, despair, fight and adaptation to the new situation, were better solved by the hypomaniac paraplegics with intense family and social connection and bearing sufficient intellectual resources with enabled them to replace their physical handicap by a certain psychic and social hyperactivity.

On the other hand, the introvert patients (schizoid), depressed (melancholia) or irritable (epileptoid) became adapted to the new situation with greater effort because they counted on less resources in the mental and social area in order to replace their deficit in the physical area and accordingly, establish a new psychic balance.

The psychotherapist tried to determine then as accurately as possible, the type of crisis and its solution for the individual and his group in the case of tragedies occurring previously to the paraplegia (death of an important member of the family, etc.) in order to favour the personal style used by the patient and his family to solve such events.

Thus, the mobility lost by the paraplegic became functionally replaced by the family leaders who were more able from this standpoint.

Finally, the prognosis also depended on the extra-family resources, vocational and social, which it previously or potentially had, and which were developed after disease, so that the family could efficiently recover its balance.

\section{TREATMENT}

As regards psychotherapeutic operations, we simultaneously work on individual, group, social and institutional levels.

(a) It was essential that the medical technical team of the centre worked in a coherent, firm and strict manner from the very beginning in order to provide the 
patient and his family with an image of security, trustworthiness and technical efficiency, which is friendly but firm.

In the ward we initially place the patient close to another paraplegic almost totally rehabilitated in order to facilitate his identification with him and encourage his hopes for improvement.

The co-ordinators systematically carried out meetings with the therapeutic team in order to provide the patient and his family with the correct information. Any word said to the patient apart from what had been planned in these meetings resulted in a massive attack of anxiety and despair on the part of the patient or his group.

The therapeutic teams were composed of rehabilitation specialists, psychiatrist consultants, physical therapists, occupational therapists, psychologists, teachers, social workers technicians in orthesis and experts in sports and recreation.

The co-ordinator (medical doctor) acted as the link between the different members of the team until the leading position became functionally filled by those members that had, at that time, a closer contact with the patient. When the utmost efficiency for every patient was obtained, we began to transmit medical-technical information to the family group, to transform it into an able commando group in order to collaborate with the paraplegic's treatment.

Right from the start the family group became included in the treatment of their paraplegic member in order to prevent the patient from being completely excluded and 'dumped' in the Institute.

We took care that the nursing personnel understood and co-operated in this spirit of therapeutic community, as well as noticed the patient's depression which may have been due to out of place reactions of the technical personnel. This was particularly so when these patients underwent psychotherapeutic treatment for their anxiety, which was really caused by deficiencies in their physical treatment. As the nurses were the ones in closer contact with the patient during the first months of treatment, we tried to help alleviate them in their role of receiver of the patient's problems, through periodic meetings and by longer medical and psychotherapeutic visits to the patient. As soon as their condition permitted, we included the patient in an environment of activity, discipline and co-operation, having them systematically rise at the routine time $(6.30$ a.m.).

At another stage, the emphasis moved once more, this time to the patient's own efforts, own but reinforced by a therapy of support and control at the Institute. Vocational orientation and evaluation of capacity for work acquired maximum relevance at this stage, as social adjustment began to coincide with the economic possibilities (Table).

(b) As regards individual psychotherapeutic treatment we had in mind three relevant items.

The first or informational consisted of the amount and quality of the information that the psychotherapist or the medical team as a whole provide to the patient as regards the degree of involvement of his disease and the corresponding prognosis. We preferred a gradual and progressive system, i.e. providing the patient with the amount of information that could help him to find his own place and co-operate without brutally transmitting the whole truth at a precocious stage. During the first months and until he becomes proficient in a certain degree of rehabilitation, we omit information on his physical prognosis except what became inevitable in order to prevent a useless and iatrogenic breakdown. When he insists on knowing 
about his physical prognosis, we tell him that we are unable as yet to correctly evaluate his physical prognosis, but insist that we are on the right track to follow the corresponding treatment, and consequently everything that could be done in this way would be for his own benefit.

\section{TABLE}

\begin{tabular}{|l|l|l|l|}
\hline \multicolumn{1}{|c|}{ Stages } & \multicolumn{1}{|c|}{ Ist } & 2nd & 3rd \\
\hline $\begin{array}{c}\text { Most important } \\
\text { activity place }\end{array}$ & Centre ward & $\begin{array}{c}\text { Centre ward and } \\
\text { technical } \\
\text { departments }\end{array}$ & $\begin{array}{c}\text { Patient's home and } \\
\text { centre technical } \\
\text { departments }\end{array}$ \\
\hline Type of activity & Medical & $\begin{array}{c}\text { Medical } \\
\text { physical therapy }\end{array}$ & $\begin{array}{c}\text { Orientation, } \\
\text { occupational, } \\
\text { definitive }\end{array}$ \\
\hline $\begin{array}{c}\text { Psychologic } \\
\text { condition }\end{array}$ & $\begin{array}{c}\text { Doubt, anxiety, } \\
\text { depression }\end{array}$ & $\begin{array}{c}\text { Acceptance } \\
\text { effort }\end{array}$ & $\begin{array}{c}\text { Social and } \\
\text { vocational } \\
\text { adjustment }\end{array}$ \\
\hline $\begin{array}{c}\text { Approximate period } \\
\text { of time varying } \\
\text { according to each } \\
\text { individual case }\end{array}$ & Days & 4 months & 8 months \\
\hline
\end{tabular}

Thus, we tell him the truth as regards the activities he has to carry out in order to prevent the possible multiple complications.

Here again 'time' as a hopeful resource, besides good medical and nursing treatment, was the word used to end up our discussion when beginning to enunciate the real prognosis.

Metaphorically speaking, we did not want to act as somebody who would comment on the mistakes in the swimming style of a person on the point of drowning, instead of throwing him the life saver he needed at that moment.

The tragedy of the sphincter incontinence, the lack of voluntary erection, etc. evidently contra-indicate the initial application of the criterion that 'it is forbidden to lie to the patient and nothing but the truth should always be told to him'. We believe that the operative partial or total negation that the patient would make of his present physical condition should be dealt with according to a wise, instrumental and progressive system. It is also necessary at the same time to bear in mind the psychological condition of the patient and the benefit obtained by providing him with such information. We consider him as a human being and give him the truth in small doses as any other therapeutic measure. That is, according to his ability psychologically to tolerate this truth. Since the 'truth' that the physician tells is not the same truth that the patient or his family hear when the patient is overcome by despair. 
After the patient has accepted his inability consciously at least we tactfully tell him the truth but without finalising it immediately. In the meantime, the dynamics and discipline of the centre will have provided him with an atmosphere of effort, recreation and above everything, self progress and collaboration.

Telling the complete truth occurred when the patient felt a useful, worthy human being again and foresaw some kind of symbolic solution to his physical problem.

The second item of the individual psychotherapeutic treatment consisted in the clearing up of the patient's fears of an infantile origin. These were already part of his previous personality and became more acute as result of the corporal scheme loss caused by his paraplegia.

We tended to transform his anxieties to help the patient to re-elaborate and accept a new body scheme, partially mutilated.

At this point we emphasised once more that the psychotherapy would not irritate these patients into taking their true physical disturbances for hypochondriac anxieties.

Still, when anxiety turned the paraplegic into a patient psychotherapeutically inaccessible, we had to work on the anxiety by resorting to the use of psychodrugs. When the anxieties quantitatively diminished and could be modified in quality by the psychotherapist, we progressively suspended the drugs.

When dealing with the family we used the same approach and care as with the paraplegic, but provided more information at an earlier stage. Through the head of the family, we progressively equipped the family as a whole with all the medical information necessary to gradually replace the centre technical group efficiently. This group training was the basis which made the patient's home return possible.

As regards the family psychotherapeutic level, the main problem was the tendency to segregate the patient and keep him inside the centre.

The steps usually were overprotection, regression, and segregation. In order to prevent segregation we had to prevent inefficient overprotection and replace it by the adequate attention that would favour the patient's progressive improvement. The group had to learn how to help the paraplegic but not deal with him as a sick child. The use of psychodrugs became useful with the most affected members of the family group.

(c) In the social and vocational therapy the most important facts were the orientation and the attention of the attending physicians and teachers to favour the previously described procedure.

\section{PROPHYLAXIS}

It was basically devoted to the strengthening of the relations between the paraplegic and his family group, the patient and the centre, and the family and the community in order to prevent this problem.

It turned out quite useful to provide the paraplegic and his family with a small manual containing practical advice. 


\section{SUMMARY}

The following is an outline of what we call 'integrated institutional therapy'.

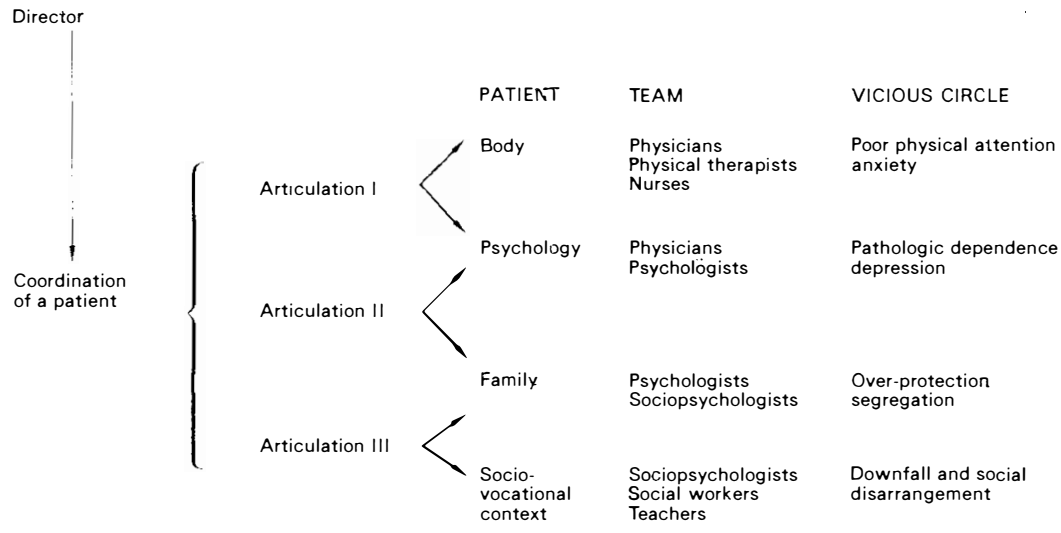

Note it shows how the centre director can control the normal relationship between all departments including the teams and the family.

This prevents an unfavourable psychological environment for the paraplegic, at the centre, at home, at work and within the community. 